\author{
Monica Nilsson \& Honorine Nocon
}

\title{
Practicing Invisibility: Women's Roles in Higher Education
}

\section{Summary}

In this article, two female academics confront their role in producing their own invisibility and irrelevance in the practice of higher education. Drawing on feminist standpoint theory, the authors interrogate their participation in articulation work that helped male colleagues to assume roles of higher status. Based on an analysis of personal narratives and the text of an international e-mail exchange that resulted in a successful grant proposal, the authors argue that the hierarchical and patriarchal cultural history of the academy as well as the intrusion of gendered relations from contexts beyond the institution of higher education undermine the democratic intentions of academics, both male and female, who espouse horizontal collaborative relations between academics. This case study illustrates the contradiction between egalitarian institutional rhetoric and value systems of individuals and the hierarchical and gendered power relations that play out in everyday life in the academy. The authors conclude that while both male and female academics must work to change the gendered text of higher education, women in the academy must build both critical mass and mentoring networks in consciously acting to change the institution's cultural history.

\section{Introduction $^{1}$}

The current discussion, or furor, in higher education provoked by the president of Harvard's recent comments regarding inherent differences in men and women as a possible explanation for the low representation of women in the sciences ${ }^{2}$ makes the work of Sandra Harding $(1987,1991)$ particularly relevant in today's academic context. In weighing the validity of feminist standpoint theory as an analytical framework for science studies, Harding argues that

The perspective from women's everyday activity is scientifically preferable to the perspective available only from the "ruling" activities of men in the dominant groups. Dorothy Smith has developed this argument most comprehensively: women have been assigned the kinds of work that men in the ruling groups do not want to do, and "women's work" relieves these men of the need to take care of their bodies or of the local places where they exist, freeing them to immerse themselves in the world of abstract concepts. The labor of women

1 An earlier version of this paper was presented at the Fifth Congress of ISCRAT, International Society for Cultural Research and Activity Theory, June 21, 2002, Amsterdam.

2 See http://www.president.harvard.edu/speeches/2005/ nber.html for the complete text of the speech. 
"articulates" and shapes these men's concepts of the world into those appropriate for administrative work. Moreover, the more successfully women perform "women's work," the more invisible it becomes to men. (1991, p. 128)

Smith (1999, p. 220) connects the invisibility of women's work in higher education to the invisibility of gender-related power in what is, historically, a hierarchical and patriarchal institution. In spite of rhetoric of democracy and collaboration, academia continues to be subject to the "stag effect" (Barnard, 1964, in Smith, 1999, p. 200), in which men asked to name those they hold significant in their field, name only men. They do not think of women students as potential colleagues, but rather, sometimes as sexual objects, sometimes as useful, and often as irrelevant.

In this article, we, the authors, who are two female academics, confront and try to make sense of our invisibility and apparent irrelevance, except as articulation workers who helped to shape places for our male colleagues to exist as principal investigators in a transAtlantic project. The purpose of this article is not to make theoretical claims, but rather to give a narrative description of how patterns of gendered inequality are played out in concrete everyday life in academia. Based on that narrative we put forward some questions the audience of this paper (whether they be individuals or collectives in the academic world) might find useful when thinking about how to promote gender equality in the highly patriarchic structure of the academic environment.

We draw on feminist standpoint theory (Harding, 1991, Hartsock, 1987, Smith, 1999) in analyzing the roles we assumed and our participation in processes that were, if not destructive (Snooks, 2002), painful and problematic to us as women and professionals. The case we use as the basis of this exploration is one in which social scientists from universities in four European countries and three US states, engaged in developing and submitting a joint proposal to fund a program of trans-Atlantic student exchanges. The exchanges were designed to expose students to the collaborators' diverse approaches to implementing a shared model for university-community research.

In spite of multiple time zones, languages, and cultures, the geographically distributed, E-mail-mediated collaboration between the researchers produced, in very limited time, a successful proposal, which was funded for three years. The authors of the present article participated in and articulated all phases of development of the grant, including conceptualization, networking and securing partners, and writing a significant portion of the text. When the grant was submitted, we were included as participants, but were not listed as principal investigators, though male colleagues who had participated minimally were listed. We had no control over funds, but were encouraged to participate in work supported by the grant, which we have done to some degree, but with far less enthusiasm than we displayed in developing the grant. Our reticence about participating as invisible laborers has contributed to difficulties in completing tasks associated with the grant, and while we continue to interact with our male colleagues, we have become wary of structural aspects of the institution of higher education that prompt us to participate against our interest as academics. We were particularly struck by the prevalence of hierarchical institutional and gender relations with male colleagues who actively espoused collaborative, democratic, and egalitarian worldviews. While the case we analyze here will not solve this contradiction, we believe it will be useful as a caveat for egalitarian male supervising professors and female doctoral and post-doctoral students. We also suggest that due to the cultural historical nature of the contradiction in which we found ourselves, a solution "outside the box" of gendered mentor/mentee relations in 
academia may be the active development of "old girls' networks."”

In the following section, we lay out our analytical framework, including the key concept of invisibility as well as feminist standpoint theory. Following that, we present an overview of the case along with our methods of data collection and analysis. We then interweave our discussion of invisibility with illustrative Email messages and excerpts from narratives we each wrote about our development as women and academics. Finally, we consider the implications of this case for men and women in academia.

\section{Invisibility}

The communicative work involved in developing a shared frame of reference is often disregarded, by which we mean left undone or, if it is done, undervalued and left invisible. This does not make the communicative work less important or less costly. Star and Strauss (1999), drawing on earlier work, describe "articulation" as a kind of communicative work 'that gets things back 'on track' in the face of the unexpected, and modifies action to accommodate unanticipated contingencies" (Star, 1991, p. 275; Strauss, 1997). They draw on Schmidt and Simone (1996) to make a distinction between articulation work "that manages the consequences of the distributed nature of work" and coordination work that "interleaves distributed tasks" (Star \& Strauss, 1999, p.10). Like Star and Strauss, Schmidt and Simone (1996) argue that articulation work, or the articulation of the distributed activities of systems that would be coordinated, is most often invisible: "it was assumed that the articulation of the distributed activities was managed

3 In the US, the "stag effect" can be seen in many institutions, particularly business and higher education, where males network with and promote males with whom they identify. These networks are commonly referred to as "old boys' networks." 'somehow'" (p.157). Their proposed solution is the use of "coordination mechanisms" or specialized artifacts "which, in the context of a set of conventions, and proceedings, are instrumental in reducing the complexity of articulation work and in alleviating the need for ad hoc deliberation and negotiation" (pp.160-161).

The effort and time required for the translation, negotiation, deliberation, articulation, and coordination in collaborative efforts constitutes a shared need for ongoing communication work that has real costs. According to Brooks (1995), the costs of this communicative work increase with the number of partners and the number of transactions necessary to establish and maintain a shared frame of reference. In the case of geographically distributed collaboration, the complexity is further increased by varied time zones, distances, and cultural diversity, as well as the need to establish virtual presence, or what amounts to a level of virtual visibility.

Once goodwill, or at least agreement to engage, has been established and a shared frame of reference starts to develop, productive actions organized by a shared object continue to be supported by invisible labor. Brooks (1995), Newell and Swan (2000), Star (1995), and Wenger (2000) expand upon Schmidt and Simone's (1996, pp. 160-161) contention that "coordination mechanisms are indispensable in reducing the complexity of articulation work and in alleviating the need for ad hoc deliberation and negotiation [in collaborative production]" (pp. 160-161). They argue, respectively that the labor of "architects," "linking pins," "wizards or gurus," and "brokers," is needed in addition to coordinating artifacts. That those who fill these roles are invisible (they often act in obscurity as "drivers" and "mechanics" of the coordination mechanisms) is not surprising, in that their work is invisible or not recognized as contributing to the final product. As Star points out "With any form of work, there are always people whose work goes unnoticed 
and is not formally recognized" (1999, p. 386). Often these "drivers" are women, who take on the role of "constructing easiness" by mediating communication in messy and hierarchical social situations (Markussen, 1995). Markussen argues that such "Boundary work has been at the core of many women's jobs" (p. 172). She gives the example of nurses as the "glue" that holds hospital work together by balancing the contradictory demands of individual human needs and rationalized medical practice. A feature of their work and all women's boundary work, according to Markussen, is women's "limitless availability" accompanied by "an inability to structure time and space [that] reflects a less powerful position" (pp. 172-173).

This invisibility of marginalized people, who Star (1999, p. 386) refers to as "nonpeople," is associated with invisible labor, but is a different phenomenon. The labor, in its invisibility, is not considered in cost analyses or planning, and therefore constitutes an unanticipated but indispensable requirement. The people whose work is not recognized are equally indispensable, but are relegated to invisibility, obscuring both their contributions and potential as resources or, alternatively, agents of restraint. On a pragmatic level, their exclusion from the planning process and consequently from the text in E-mail-mediated collaboration obscures real labor needs and resources that can inform the shared frame of reference. On a moral level, to leave them and their labor invisible contributes to a social construction of authorship that is potentially exploitative.

In summary, collaborative work among diverse actors poses challenges related to invisibility, specifically invisible labor and laborers. Invisible laborers are most often women and the invisible tasks they perform, like articulation of collaborative endeavors, because they are "women's work," are generally undervalued or considered irrelevant.

\section{Feminist Standpoint Theory}

Dorothy Smith explains how she developed her interpretation of feminist standpoint theory through a brief narrative of her experience of being a mother of two small children while working at the University of California at Berkeley (1999, p. 47). She says the experience required her to know the particularities and actualities of practice associated with mothering while also knowing the sociological "worldin-texts" with its "extra-local" ruling relations. She adds that being a mother gave her a site of experiential and practice-grounded knowing that was prior to the extra-local academic world-in-texts. She clarifies that this does not mean "working subjectively; rather, it means working from a site of knowing that is prior to the differentiation of subjective and objective. It means an explication of the actual practices in which we are active"' (p. 49), what she calls an "insider's sociology." Smith points out that recognition of the insider's marginality in historically hierarchical gender relations provides feminist social scientists with a unique perspective that requires knowledge of both the events that occur in practice and the woman's perspective on those events, which is likely to differ from that of the rulers, i.e., the historical, patriarchal perspective.

According to Harding (1991, pp. 121-131) feminist standpoint theory assumes that women's lives have been erroneously devalued and neglected in social science and that women are strangers or outsiders to the social order, which gives them valuable insights. To paraphrase Harding, because women are outsiders, they have little interest in maintaining the status quo. Their perspective is from the losing side of the battle of the sexes. The women's perspective is from everyday life; it therefore grounds or links science or social science to lived practice. Therefore, women researchers are "outsiders within." Harding concludes that women assume a standpoint that is inherently different from that of the rulers, in that 
they relate to the rulers and social phenomena from a different position, one of historical oppression.

Hartsock, drawing from Marx, points out that "A standpoint, however, carries with it the contention that there are some perspectives on society from which, however well intentioned one may be, the real relations of humans with each other and the natural world are not visible" (1987, p. 159). In other words, the rulers, i.e., males, cannot see things from the women's standpoint, and women themselves may question the validity of their standpoint. Hartsock attributes this to five factors. First, material life sets limits on the understanding of social relations. Second, "In systems of domination, the vision available to rulers will be both partial and perverse." Third, "The vision of the ruling class (or gender) structures the material relation in which all parties are forced to participate, and therefore cannot be dismissed as simply false." Fourth, "In consequence, the vision available to the oppressed group must be struggled for and represents an achievement which requires both science to see beneath the surface of the social relations in which all are forced to participate, and the education which can only grow from struggle to change relations." And, fifth, "As an engaged vision, the understanding of the oppressed, the adoption of a standpoint exposes the real relations among human beings and points beyond the present, and carries a historically liberatory role" (pp. 159-60).

Harding (1987, p. 8) argues that feminist research, including feminist standpoint theory and methodology, has the goal of providing women with "explanations of social phenomena they want and need." She adds, "feminist inquiry joins other 'underclass' approaches in insisting on the importance of studying ourselves and 'studying up' [from women's oppressed position] instead of 'studying down' [from that of the rulers]."

Before leaving this section, it is useful to add a note about narratives as data in femi- nist inquiry. Bloom (1998) describes feminist inquiry as dialogic research that produces relationships. She argues that a feminist perspective attends to and is non-judgmental regarding personal narratives. This is based on an assumption that narratives are offered in a relation of goodwill and in the interest of trying to make sense of personal experience. Smith used her Berkeley experience in this way, but adds that an approach that is open to narrative is not necessarily devoid of rigor. Chapman and Sork (2001, p. 98) deal with the issue of rigor by asking of narratives, not whether they are true or valid, but if they illuminate an area of practice in a way that was helpful to others. They also ask how narratives relate to theory.

Before moving to a discussion of the methods used in data collection and analysis in this case study, we provide a brief overview of the case.

\section{A Case of Gendered Collaboration}

In late 2000, researchers at a European university (Nordic $\mathrm{U}$ ) became aware of a funding opportunity that would support the exchange of university students between universities in Europe and the United States. These researchers had, for three years, been engaged in informal exchanges with researchers at a US university (Western US U), as well as other universities in the US and Europe. Their informal exchange was built around a shared model for university-community collaboration that involved research, teaching, and community outreach. Work with the shared model appeared to provide both a history and an informal infrastructure that would support the exchange of students.

During one of the informal exchanges, researchers from Nordic U secured the commitment of researchers from Western US U to pursue the grant. The first task was to secure the 
commitment of two additional universities in Europe and two in different US states. Nocon, who was from Western US U approached researchers at Eastern US U and Mountain US U and, in early April 2001, secured their commitment to participate. The US collaborators negotiated which US university would take the lead, and assigned the role to Eastern US U. Researchers at the three US universities began to work with the administrations and bureaucracies of their respective universities, anticipating submission of the proposal in late May.

In early May, the lead researcher (male) from Nordic U communicated doubt that the proposal process could move forward as no commitment to participate had been secured from other European universities. In another exchange in Europe, a meeting formalized by recent funding of a different grant, Nocon (from Western US U) and Nilsson (from Nordic $U$ ) persuaded a male colleague from Nordic $\mathrm{U}$ as well as other members of the Nordic U research team, to pursue the grant proposal and take the lead among the Europeans. Representatives from two other European universities (Mediterranean U and Baltic U), who were at the meeting as participants with Nordic U, were approached about participating, but commitment was not secured at that time.

E-mail exchange between participants from the three US universities and Nordic U began in late April. Commitment to participate was secured from a new European university (Northern U) in early May. Commitments from Mediterranean U and Baltic U were eventually secured shortly before submission of the grant proposal. While representatives from each of the participating universities contributed to the jointly-produced text of the proposal, the bulk of the writing involved six of eighteen persons who participated in the E-mail exchange. These six included three males who assumed the role of principal investigator at the three US universities and the male who was principal investigator at Nordic U. The other two most active participants were the two female researchers, one from Nordic $U$ and one from Western US U, Nilsson and Nocon, who are the co-authors of this paper. The proposal was submitted hours before the European and US deadlines after considerable coordination, writing, editing, and compilation efforts by the European and US leads, who were male. The collaborative writing process that produced the proposal took place on E-mail during a period of 33 days. The final version of the proposal included the names of eight principal investigators, all males, one each from the four European universities and two US universities and a dyadic team from the third US university.

In the course of producing the proposal, eighteen persons participated in a process that yielded 407 E-mail messages between participants as well as a collaboratively produced text. Most (397) of the messages were sent during the five weeks prior to submission of the proposal. Table 1 illustrates how production of these messages was distributed. As noted above, six persons generated nearly all the messages. Of these six individuals, five had collaborated continuously since 1996 . Two began their collaboration in the early 1990's. The sixth collaborator (Mountain US U, male 1) was quite new to the other five, having met researchers from Western US U a month or two before committing to participate in the project. The twelve other participants who sent messages, with one exception, sent introductions or specific pieces of text. The one exception was a message from an administrative staff person at Western US U, who wrote on behalf of herself and a female administrative staff person at Eastern US U. Both had urgent needs for documents in order to satisfy the bureaucratic demands of their respective institutions.

The information in Table 1 illustrates the marginality of Nocon and Nilsson, the two female participants, as well as the power associated with professional positioning. While 
Table 1. Messages sent by most active participants

\begin{tabular}{|l|c|}
\hline Participant: & Number of messages sent: \\
\hline Eastern US U male & 162 \\
\hline Western US U female (Nocon) & 85 \\
\hline Nordic U male & 29 \\
\hline Western US U male & 27 \\
\hline Nordic U female (Nilsson) & 27 \\
\hline Mountain US U male 1 & 373 of 407 messages \\
\hline Total: & 29 \\
\hline
\end{tabular}

Nocon and Nilsson made substantial contributions to the text, male participants from Mediterranean U, Baltic U, and Northern U, and a second male from Mountain US U, who contributed minimally, were named as principal investigators and represented in the submitted text as authors. Their positioning and utility to the process rendered them visible, while the lower status of the female, and far more active, participants rendered them invisible.

\section{Methods}

After the grant proposal was submitted, the authors of this paper remarked on their absence from the representation of authorship (i.e., the list of principal investigators) of the joint proposal. Reflecting on that absence in the context of the intense labor we had dedicated to the collaborative endeavor, we approached the other proposal authors and secured their permission to analyze the E-mail archive of the exchange for the purpose of producing an article about what had been learned in the process.

Adler and Adler (1987) describe several roles that researchers can take in the field. They range from complete observer to complete participant and are drawn from the Chicago School, existential sociology, and ethnomethodology. Adler and Adler describe the role of complete participant in terms of "becoming the phenomenon" (p. 25). In the case of the proposal, we, the authors of the present article, co-produced both the text and, we believe, our invisibility.

Aware of the potential for conflict of interest and bias, we engaged in what Heath, Koch, Ley, and Montoya (1999) describe as "location work" (p. 451):

Location work recognizes that (a) anthropologists [and other researchers] are inextricably linked socially and politically to the situations we study, (b) our relationships to our informants' lives are configured in fields of unequal power, and (c) the knowledge gained through our relationships is necessarily political.

In our case, the knowledge gained in analysis of this case caused us to wish to make sense of our participation in the processes of production, both of the text and our marginality. Following Smith, we have assumed a feminist standpoint that is one of neither subject nor object, but both. Because we were so completely involved in the production of the proposal, we chose first to locate ourselves and our collaborators outside of the object of our analysis, i.e. invisibility, and to restrict our analysis to the E-mail exchange and events recorded there. We acknowledge that an E-mail record 
is only partial. We have found, however, that a focus on the text record served as a test of our memories and, three years after completing the process, provides documentation that suggests a perspective broader than our own. Additionally, working from the text replicates the experience of the collaborators.

On the other hand, time and distance from the text of the E-mail exchange have contributed to our desire to make sense of our participation in the process of producing our invisibility as well as that of our well-meaning male colleagues. In order to do that, each of us female co-authors produced a historical narrative of our lives as women and academics, similar to that used by Smith to develop her understanding of a feminist standpoint. We have drawn on these narratives in our analysis of the process made evident in the E-mail exchange.

Early in the writing process, the lead from Eastern US U set up a listserv to support the distributed collaborative writing process. Nilsson kept an archive of all messages and attachments sent to her personally (71) or to the listserv (336). Our analysis of the texts of the E-mail exchange was originally based on the frequency with which participants sent messages, emergent categories of content, and phases in the work process. Our inter-textual analysis with our narratives was based on rereading the E-mail exchange from a feminist standpoint.

\section{Making Sense of Invisibility}

Recall that the collaborative process that produced the grant proposal took place on E-mail during a period of 33 days. Content analysis of the E-mail text (407 messages) indicates a concern with presence and visibility. Due to other commitments, the European lead was missing from Day 13 through Day 18, a crucial time for coordination. The lack of messages during that phase, as well as what can be called a comparative reticence in terms of number of messages sent from European participants, prompted messages from US participants asking things like: Where is $\mathrm{X}$ ? Is X dead? Below is a milder example:

\section{From: Eastern US U male \\ Date: Day 15 \\ To: Nocon at Western US U \\ Subject: Re: personal}

What is the situation with the Europeans and Nordic U male? They are pretty quiet?

The absence of those representing Mediterranean $U$ and Baltic $U$ was similarly noted. The following message from Nilsson represents how the female participants carried out the "women's work" of communication and articulation, helping to make the male participants visible to one another or, in line with Harding, taking care of their virtual bodies and locations.

\section{From: Nilsson at Nordic U}

Date: Day 21

To: Eastern US U male, Nordic U male, Nocon

Subject: RE: specific questions/points

I just got a message from Nocon. She is off-line - her network connection broke. She urged you to find out what partners are in and what role they will play, for example DL[distance learning], student exchange, etc. This is crucial for the budget.

Nordic U male, are you on line - what is going on? Western US U male is waiting to hear from you what you want him to do.

Time is running out!!!!!

As late as Day 26 (of 33), the US lead was asking where the EU lead was and if anyone knew whether Mediterranean U and Baltic U would, in fact, participate. Others sent messages asking for phone numbers, trying to use different communication media to track down less communicative participants. In the case of Mediterranean U, translation of messages into 
the participant's native language, provided by Nocon, was used:

\section{From: Nocon}

Date: Day 29

To: Nordic U male, Eastern US U male, Nilsson Subject: Fwd: Mediterranean U male URGENT I've just heard from Mediterranean U male. I sent him a message last week saying we needed to know who we should ask for signatures and letters of support. Below is a translation of his response. Note the addresses in his response. If you need me to send something in [his native language], I will. Unfortunately, I need to sleep. But, I will stay up for a little and be awake at 4:30PST (1330 Nordic U time) ps: Eastern US male, I'll get to the charts then, too.

(Translated excerpt of forwarded message): Pardon my long disconnection (long time away from E-mail). Last week I was working 11 hours a day [in a university in rural South America]. Ok. Tell me exactly what you need. The addresses are those at the head of this E-mail. Messages in English can be read by Mediterranean $\mathrm{U}$ female and Mediterranean U male $2 \ldots$ we will not return to the city until [21 days after the grant deadline] I don't yet know if I'll be able to check E-mail.

This message from Nocon provides further evidence of communication and articulation as well as the "women's work" of translation, performed by Nocon. In addition, the reference to staying up late and waking early in order to work on the grant is evidence of what Markussen (1995, p. 172) described as women's "limitless availability." That limitless availability, according to Markussen helps to construct the invisibility of "women's work."4

4 We should point out here that Nordic U male, the European lead, did engage in some extraordinary articulation and communication work as well. When it became clear that Mediterranean U male was indeed absent, due to a research trip to a remote jungle area, the European lead made a trip to Mediterranean U in order to deal directly with administrators.

\section{Invisible Labor}

A significant portion of the E-mail messages dealt with building collaboration/negotiating a shared object (111 of 407 messages). These referred to locating copies of the RFP (request for proposals), interpreting the criteria and design specifications, discussions of design and budgets, clarifying who was on board and negotiating the division of labor. Because presence was text based and communication was asynchronous, the lack of a protocol for announcing who was working on what and where they were in accomplishing the work caused confusion and some duplication. A serious need for articulation work surfaced on day 17 , when it became apparent to Nilsson that the collaboratively written text produced as of that date did not correspond to the RFP. Nilsson and Nocon sent messages questioning whether participants were working from the same grant guidelines.

\author{
From: Nilsson \\ Sent: Day 17 \\ To: Nocon \\ Subject: FW: Background/Need \\ I have the same problem with this [previously \\ sent block of text], where does it fit? \\ I will not do anything until this is clarified. \\ Are we working on different application forms?
}

This was followed by Nilsson sending out the funding agents' URLs for the application forms and guidelines
From: Nilsson
Date: Day 17
To: Listserv
Subject: Forms to fill out
Hi everyone,
It is time to fill out some forms. Please go to this site:
http://xxxxxxxxxxxxxxxx
Go to Application forms and click on the square that says:
Go to section 4 and 5 and fill them out. Mail
them to Eastern US U male 
and he will put them together in one document.

As said before you can also have the application form in

your own language but the one you fill out and mail to Eastern US U male

has to be in English.

In addition to locating the forms, Nilsson and Nocon read the European and US RFPs carefully and "translated" them for the other participants. Making the discoordinations visible as well as their remedies (e.g., jointly reading and articulating steps for complying with the RFP) was preceded by invisible work. This invisible background work led directly to the need for articulation perceived by the female participants, who acted on that need and shared the results with the male participants. For example:

\section{From: Nocon \\ Sent: Day 17 \\ To: Listserv}

Subject:

All that said, I have just spent time slowly reading over the guidelines and the application. Some things really stand out. For example, while both sides submit the same proposal, the forms are different...

Both call for "student (meaning university/college student) centered projects with potential to stimulate substantive and long-lasting structural transatlantic cooperation in higher education and vocational education and training." I read this as meaning that our focus has to be on our university students and the adults we work with in our communities.

In reading both your research references and discussion of needs, (which, BTW are incredibly valuable documents for all of us), I think there is too much emphasis on the kids... Not that we don't feel that they are the most important part, but this grant is about students and practitioners. I think we can use parts of all the proceeding documents to write a draft that specifically addresses the points in the guidelines, section 10 a, $\mathrm{b}$, and $\mathrm{d}$...

In retrospect, the message above fairly drips with diplomacy! More seriously, the message illustrates articulation work that sets danger- ously wayward things back on track. The persuasive and consoling tone can be read as cloying, however, it also represents the hierarchy of student/professor, female/male relations. Similarly, when we, Nocon and Nilsson, were also concerned that no one appeared to be taking a directive role, Nocon sent a message which spelled out a potential division of labor and called for more directive leadership in terms of assigning tasks. This elicited the following response to the listserv from Nilsson:

Thank you, Nocon, I think Nordic U male and Eastern US U male have to be the

"Bosses" from now on and tell us what to do...

which was, in turn, followed by more directive messages from Eastern US U male that served to coordinate the actions of the distributed participants. For example:

\section{From: Eastern US U male \\ Date: Day 22 \\ To: Listserv \\ Subject: Volunteer task}

\section{Exchangies}

Nordic U male and I need to know the tasks you will volunteer for. We will wait a short time and then do our best guess at assigning you one if we don't hear from you....

While Nilsson's response was not exactly cloying, it is reminiscent of the speech patterns of women who must "suggest," rather than direct. ${ }^{5}$ Interestingly, the role that we, Nocon and

5 This time-honored, but demeaning, form of considered, indirect persuasion is a skill that Betty Freidan (1963) described and interrogated in the Feminine Mystique. The authors were young women during the Women's Movement and had been raised to learn the nuances of getting what one desired or wanted from the "rulers." In spite of the Women's Movement, these skills and the perceived need to use them in male-female relations persist amid ambivalence among female university students (see Holland \& Eisenhart, 1990; Holland et al., 1998). 
Nilsson, wished someone to assume (because we could not) was consistent with Brooks' (1995, p. 256) role of "architect," or "one who is responsible for the conceptual integrity of all aspects of the product..." and "forms and owns the mental model." Although as females and students we could not assume the role, based on our concern and involvement in the grant project, we essentially constructed the role for the leads by working behind the scenes. As Markussen (1995) suggests, we two women took on the work of being the "glue" in the collaboration, pulling it together and giving it direction, indirectly. We continued to make ourselves limitlessly available. Our work was communicative, involving reading, translating, and coordinating, tasks that generally went unrecognized. Our labor became officially invisible when the grant was submitted under the names of the eight male principal investigators, as mentioned earlier. We will return to that, but first we note that invisible work relegates those who do it to the status of invisible people.

\section{Invisible People}

The two female participants and co-authors of this article were extremely active in the grant development process and in writing the text of the proposal. Upon submission of the grant, our marginality as females who were also junior academics (doctoral student and postdoc) became visible. We were, however, listed as grant participants. There were others who played an active role in producing the proposal who were, if visible at all, only glimpsed.

Text production was the theme of 236 messages and involved sending drafts, sending edits, comments and re-writes, generating and sending budgets and assuring that required letters and forms would be sent to the European and US leads in time for submission. The generation of budgets and compilation of grant packages were not trivial tasks, but the people who actually produced the final grant applications at each of the universities were almost completely invisible to the grant-writing process, and almost exclusively women. For example, the message below alludes to an administrator who negotiates with the university's bureaucracy, administration, and copying services.

\section{From: Western US U male \\ Date: Day 23 \\ To: listserv \\ Subject: Nocon-Nordic U male Eval \\ Hi All-Nocon is on the phone with [the admin- istrator] and we are sending forms to Eastern US $\mathrm{U}$ male and it appears that things are coming to- gether. Amazing process.}

This individual [the administrator] participated in producing the grant budget with input from the researchers. Without her knowledge and handling of formal university grant procedures, all of the grant writing and wringing of hands would have been futile. Her work was to link the grant writers (the academics) with other actors at the university. In other words, she and her multiple counterparts at all seven universities constituted an essential part of the grant writing process. While essential, their work was officially non-existent--invisible. Their names appeared nowhere in the finished text, and very rarely in the E-mail exchange. They were, as Star (1995) suggests "nonpeople." As nonpeople, the staff members that supported the grant-writing process were less visible than the two female students, who were "nonauthors" but were people recognized publicly in the collaborative process.

Nonpeople become visible when discoordinations emerge and require action. For example, as with many grant proposals, when deadlines have passed, administrative staff can ease documents through the bureaucracy by drawing on their professional relationships and histories of exchanging favors. If alienated or unmotivated, these same nonpeople have the power to block the process, a course of 
action by which they rapidly make themselves visible.

A challenge to those who "author" the product, in this case the text of the grant proposal, is to recognize that nonpeople are both essential to the process and marginalized. Recognizing this marginalization is difficult for those whose professional positioning (and gender) place them in positions of power. For example, on Day 29 (of 33), Nocon sent a message to the US lead humorously referencing the invisible labor in the proposal production process. The US lead's response was to publicly acclaim the behindthe-scenes labor of the European lead, a male, in finally securing the commitment of participation from Mediterranean $\mathrm{U}$ and Baltic U: "While we have been delivering visible text here on monitor stage, the European lead has been working diligently and unseen off-stage. Ken Burke suggests that it is the off-stage activity that really creates the on-stage activity" (Eastern US U male, Day 29). This came at a time when the two female participants, Nocon and Nilsson, were dedicating numerous hours behind the scenes each day to the grant production process, not only in text production, but also in securing the participation of Baltic U. Though our contribution was noted locally, "...there was a little invisible labor going on. Actually, not so invisible if you were in the right location!" (Western US U male, Day 33), this exchange between the leads was demoralizing and demotivating, particularly when our marginality was represented by our absence as authors when the grant was submitted. It brought home to us our position in the professional hierarchy and the invisibility associated with our "limitless availability" (Markussen, 1995). Like alienated and unmotivated "nonpeople" we quickly became less available.

When the US lead publicly acknowledged the European lead for his contribution of invisible labor, the European lead publicly ex- pressed his thanks and reminded all that there were many contributions to the process that had likely remained invisible. Though this particular exchange and the collaborative process on the whole were characterized by goodwill, it is not clear that the marginality of the two female participants, nor that of the (mostly female) administrative staff came to the attention of nor constituted a moral dilemma for any of the male professors who participated. Even for us female participants, visceral awareness of the hierarchical relations that constrained recognition of our participation emerged only slowly, in the process of producing the grant. For us, this was a process of raising our consciousness. We will return to this below.

In a brief series of messages as the grant process ended, the US lead did address one form of invisible labor-labor that is needed but remains undone. This labor, which includes liaison work or coordination, articulation, and making visible (i.e., record-keeping, posting project status each day) is essential and should be taken into account in designing and undertaking distributed collaborative work. The call for addressing this form of invisibility dealt with pragmatic or instrumental aspects of the collaborative process, perhaps in line with what Schmidt and Simone (1996) call "coordination mechanisms." As such, this form of labor was meant to be a tool for mediating distributed collaborative work. What the US lead's call did not address was the invisibility of labor done and not recognized, nor the invisible and marginalized people who perform that work. These aspects of collaboration are integrative and moral as opposed to purely pragmatic. Making nonpeople, their labor, and their marginality visible is a greater challenge. The E-mail collaboration described here is a case in point. The most active male participants espouse a shared ethos of democratic social relations. However, the supporting structures of the universities in which they, 
and we, work prescribe hierarchical relations (e.g., staff, graduate students, faculty) that underlie and belie horizontal collaboration. Kronsell (2002) describes this contradiction as "formally articulated pluralism vs. informal paternalism" (p. 52). Additionally, the societies in which the European and US participants live and work have constructed historical and cultural inequalities in gender relations that pervade activity and practice. As Markussen (1995) and Star (1995) suggest, the inequitable gender relations are the product of the culture's history and are reproduced in current activity mediated by that culture, even when those activities are associated with higher education's discourse promoting pluralism, democracy and collaboration.

But where does that leave us? Are we, academic males and females, hopeless prisoners of history? If we are agents, are we females as complicit as our male colleagues in reproducing our marginality? When we resist our marginality, do we participate in a "dance of anger"6 from which we should, for the sake of our dignity and social justice, withdraw? But, if we withdraw from the gendered dance of higher education, how can we survive, much less thrive, as academics? As Valerie Chapman (Chapman \& Sork, 2001) a female master's student wrote in her journal regarding her meeting with the best candidate to become her thesis advisor, in spite of the fact that he opposed Valerie's feminist approach, "Who needs this stuffy American white man, I fumed, while I smiled tactfully. I do" (p. 97).

If we are to survive in academia, we do need to work with, interact with, and be mentored and sponsored by males, who still constitute a

6 In her book, Dance of anger, Lerner (1985) argues that women who are in oppressive relationships are the ones who see the need for change as well as the ones who must initiate change by removing themselves from the destructive dance. very healthy majority of tenured professors. ${ }^{7}$ But, how do we negotiate a more equitable way of interacting that allows us to maintain personal and professional dignity while working productively with our male colleagues? Kronsell (2002), who found herself "homeless in academia," argues that the reasonable response of women academics to the paternal authority structure of higher education is radicalism. She describes this as the path she and her female colleagues took at a venerable Swedish university when the gendered power structure became visible to them.

Using a psychoanalytic analysis, Kronsell explains the difficulty women have in seeing the gendered nature of higher education. In addition to the rhetoric of egalitarianism and pluralism, she argues that the informal paternalism of higher education, or the intrusion of gendered relations from outside the institution, constructs female academics as "rambunctious daughters" (p. 50). Because the "mothers" in higher education are most often administrative staff people, rather than professors, women academics have few female models and must depend on male mentors and sponsors. The males on whom they depend often give the rambunctious daughters what they ask for. However, "In the end, it is the son who follows in the father's footsteps, takes over, and honors his legacy" (p. 51). Because she gets things she asks for, the daughter is caught off-guard by signs of her irrelevance until she learns to become bi-textual, reading the mainstream

7 Astin \& Cress (2003) compiled demographic data on women in higher education in the US. They found that while women make up about $35 \%$ of faculty at institutions of higher education, they make up only $28 \%$ at research universities and are more likely to be employed by four- and two-year colleges than universities (p. 54). Additionally, at the lower levels in the academic hierarchy across all institutions, including assistant professor, lecturer, and instructor, women outnumber men. At the associate professor level, numbers are essentially equal. At the level of full professor, men outnumber women by more than two to one (p. 57). 
text and rhetoric as well as the feminist text (p. 46). Kronsell's emerging bi-textuality led her and her female colleagues to radical womenadvocacy. They joined together to fund their work, change curriculum, and create a critical mass of women who could collectively build a support network through the resistance that the "gendered nature of the institution makes possible" (p. 48).

Kronsell's narrative resonates deeply with our own experiences. She describes gendered behavior in seminars and classrooms that is very familiar. ${ }^{8}$ Similarly, the slow emergence of raised consciousness is very similar to what we, the authors, experienced in this grant-writing process. We became, in essence, bi-textual as we co-produced the grant text with its official representation of male dominance and at the same time became aware that we were producing our own invisibility, as is described in an excerpt from Nocon's narrative:

The grant-writing experience was a challenge in several ways. It was originally proposed by a male colleague at a European university, who had "taken care" of me, along with his colleague, my female friend and colleague from his university [Nilsson]. I felt this was an opportunity to continue to collaborate and also to bring in people I wanted to work with. Therefore, I had mixed motivations for participating in the process. Some were instrumental and some were integrative. In terms of my mentor and advisor, I was also "taking care" or acting in service to his work, which I felt strongly was going to be sustained by international collaboration.

I was written into the grant at my postdoc university. I later moved to another university partner. While my name remained on the grant, I was not "officially" there and the grant did not follow me.

8 The women were quiet or silent, hardly moving, occupying little space, but "they [the males] could often sit with their legs spread apart, arms crossed behind their heads, even rocking back and forth on the chair, as if trying to fill more and more of the space in the seminar room" (Kronsell, 2002, p. 41).
My continued participation was dependent on the largesse of two males at the new university, who I, ironically, brought into the grant, which, again ironically, I heavily co-authored with my female European friend and colleague. Similar to me, her official standing in the grant is not clear, due to moves and structural changes at her university. The most telling thing is that we, who led the work in developing the grant, are not principal investigators, while our male colleagues, most of whom participated only peripherally, due to their positions, are principal investigators. I remain dismayed about that. I recognize that some of it is due to the student/professor hierarchy. I believe some is due to the male/female hierarchy in higher education. But, I also believe that some of it is due to my willingness to serve and support.

The willingness to serve and support, to be limitlessly available, is a reflection of the "mothers" who often serve as models in higher education, the administrative staff members. It is also an intrusion of life beyond the institution. It is used by males in the academy, but not valued or respected, which suggests that Kronsell's call for radicalism be interpreted as a call to eschew, suppress, and eliminate that aspect of women's experience, if one wishes to be a woman in the academy. However, a feminist standpoint requires that the lived practice which characterizes women's lives have a place in a new hybridized text which blends both mainstream higher education and feminine experience. Both authors of the present article, like Smith, are mothers, our academic formation was accompanied by participation in practices that gave us a site of knowing that was prior to the text of the academy. That site of knowing in the particularities and actualities of mothering is in our bodies, our identities, our understanding. We know its intrinsic value and its value in research, where we are outsiders inside, with a different lens than that of the rulers, males.

Like Kronsell, we believe that a critical mass of women in the academy is necessary for change in the text of the gendered institution. 
Unlike Kronsell, our academic situations did not allow us to build a local, radical women's faculty group at the universities in which we did our doctoral work, or those in which we are currently employed. However, we are able to network, and we can, as Kronsell did, serve the interests of other women in the academy, students and colleagues, even as we are careful not to be rambunctious, but servile daughters, to our senior male colleagues. Nilsson's narrative captures this standpoint:

Myself, I worked as a nursery school teacher several years before entering the road to become a Ph.D. in education. After finishing senior level, high school seemed too much of a challenge to me. I was expected, though not supported academically, to continue to high school by my parents, but my self-confidence deceived me and I took a job as a nanny in a family instead. After two years in nursery education I worked as a nursery school teacher for 15 years. During this time I was also active in the teacher's trade union. My attitude was that of "working for a good cause" and career was not a concept guiding my steps. Despite the fact that I liked the job, I felt a need to move on. I knew I had qualities and a drive that was not satisfied in my job as a nursery school teacher. With my two children now being teenagers (I raised my children as a single mother) the time had come for me to do what I wanted - get a university degree. I had to start with a high school diploma, continue with a bachelor's and a master's. I ended with a Ph.D. and a professorship in education.

It took me a long time to learn the academic "paradigmatic" discourse and many times I felt stupid, imprisoned, and was prepared to give up. An inner voice however - encouraging me to stick to my beliefs - guided me through the hardships. Not to mention friends and colleagues (often women) embarking on the same road. Not until now is my identity slowly stabilizing from one of a nursery school teacher to one of a university professor. With this comes a feeling of power, confidence, maturity, and happiness.

In the rest of my work life I want to set the agenda and get something "career wise" out of it. I want to be competent and develop my gifts. I will no longer only serve the "good cause," be an activist and do bargaining work. I also want to make sure that I and my "sisters" get ahead and get roles that make it possible for us to experience the pleasure that comes with an academic and "respected" position. The good cause should involve me, too.

Working on the trans-Atlantic grant project was valuable for us as women and as academics. We have experienced professional growth through the exchange of graduate students and researchers and we continue to interact amicably with our male colleagues. We do not, however, take responsibility for articulation of the project, nor do we take responsibility for elements that may not get done because invisible labor is not provided. We have learned to limit our availability. We have also begun to build our old girls network, recognizing that our best models are other women academics in higher education, who, like us, are outsiders, on the inside.

\section{Practicing Visibility}

Recognizing the hierarchical and gendered cultural historical frame of higher education is useful in both design and analysis of distributed, collaborative academic work. Relations assumed to be horizontal mask differential distributions of power that confound even those who embrace a utopian vision. Would-be change agents are also prisoners of history, until they gain access to and understanding of alternative histories that are obscured or invisible to those in power and often those who are not. Those who provide invisible labor, once their consciousness is raised, must weigh the costs and potential benefits of entry into a domain that has historically been both hierarchical and male-dominated against refusal to participate on principle.

We have asked ourselves what would have been an approach to this grant writing that would have been agreeable or satisfactory to us. We were named in the grant as participants, and due to bureaucratic constraints, could not 
be listed as principal investigators. We would have appreciated formal and informal recognition of the work we did, the role we played. In retrospect, however, we believe we should not have taken on the articulation of this project. The costs were too high. In spite of benefiting from the grant, as noted above, we must regularly confront our official invisibility. We also see and regret things we might have done, but have not, because we have limited our availability.

In spite of this, we acknowledge the goodwill of our well-meaning male colleagues. We suggest to them and all males in the academy that they treat academic women, particularly students, not as daughters, but as future colleagues and peers, though perhaps as colleagues and peers from another culture, which is different, but valuable. Through cross-cultural, or cross-textual, interaction, all academics can gain new insights based on perspectives that are different, but worthy of dialogue, and possibly integration.

This is, however, a utopian vision. Higher education does not honor women's knowledge based on our particular experiences, in spite of greater participation of women. A radical feminist perspective would claim that men cannot see things from the women's standpoint and they have little incentive to do so, or to change the status quo since they are the rulers. Why should they abdicate? A more pragmatic perspective, which we choose here, is to say that the discourse in academia needs to change so that it welcomes gendered multiplicity. For this reason, it is essential that women in higher education serve one another, building a critical mass, and thereby contribute to a change in the cultural history of the academy. We need a change which opens up the dominant text and blends it with the text of women's experiences and ways of knowing - a feminist standpoint- so that women and women's labor become visible and respected as valuable and acknowledged resources to all in the academy.

\section{References:}

Astin, H.S., \& Cress, C.M. (2003). A national profile of academic women in research universities. In L.S. Hornig (Ed.), Equal rites, unequal outcomes: Women in American research universities (pp. 53-88). New York: Kluwer Academic/Plenum.

Bernard, J. (1964). Academic women. New York: New American Library.

Bloom, L.R. (1998). Under the sign of hope: Feminist methodology and narrative interpretation. Albany, NY: State University of New York Press.

Brooks, F.P. (1995). The mythical man-month. Reading, MA: Addison-Wesley.

Chapman, V., \& Sork, T.J. (2001). Confessing regulation or telling secrets? Opening up the conversation on graduate supervision. Adult Education Quarterly, 51(2), 94-107.

Freidan, B. (1963). The feminine mystique. New York: Dell.

Harding, S. (1991). Whose science? Whose knowledge? Thinking from women's lives. Ithaca, NY: Cornell University Press.

Harding, S. (1987). Introduction: Is there a feminist method? In S.G. Harding (Ed.), Feminism and methodology: Social science issues (pp. 1-14). Bloomington, IN: Indiana University Press.

Hartsock, N.C.M. (1987). The feminist standpoint: Developing the ground for a specifically feminist historical materialism. In S.G. Harding (Ed.), Feminism and methodology: Social science issues (pp. 157-176). Bloomington, IN: Indiana University Press.

Heath, D.; Koch, E.; Ley, B.; \& Montoya, M. (1999). Nodes and queries. American Behavioral Scientist, 43(3). 450-463.

Holland, D., \& Eisenhart, M. (1990). Educated in romance: Women, achievement, and college culture. Chicago: University of Chicago Press.

Holland, D.; Lachiocotte, W.L.; Skinner, D. $\&$ Cain. C. (1998). Identity and agency in 
cultural worlds. Cambridge, MA: Harvard University Press.

Kronsell, A. (2002). Homeless in Academia: Homesteading as a strategy for change in a world of hegemonic masculinity. In J. DiGeorgio-Lutz (Ed.). Women in higher education: Empowering change (pp. 3756). London: Praeger.

Lerner, H.G. (1985). Dance of anger: A woman's guide to changing the patterns of intimate relationships. New York: Harper \& Row.

Markussen, R. (1995). Constructing easinesshistorical perspectives on work, computerization and women. In S.L. Star (Ed.), The cultures of computing (pp. 158-180). Cambridge, MA: Blackwell/Sociological Review.

Newell, S. \& Swan, J. (2000). Trust and interorganizational networking. Human Relations, 53 (10). 1287-1328.

Schmidt, K., \& Simone, C. (1996). Coordination mechanisms: Towards a conceptual foundation of CSCW systems design. Computer Supported Cooperative Work: The Journal of Collaborative Computing, 5. 155-200.

Smith, D. E. (1999). Writing the social: Critique, theory, and investigations. Toronto: University of Toronto Press.

Snooks, M. K. (2002). Expanding the academic knowledge base: Helping students to cross gender's great divide. In J. DiGeorgio-Lutz (Ed.). Women in higher education: Empowering change (pp. 5-20). London: Praeger.

Star, S.L. (1999). The ethnography of infrastructure. American Behavioral Scientist, 43,(3). 377-391.

Star, S.L. (1995). The politics of formal representations: Wizards, gurus, and organizational complexity. In S.L.Star (Ed.), Ecologies of knowledge (pp. 88-118). Albany, NY: State University of New York Press.

Star, S.L. (1991). Invisible work and silenced dialogues in representing knowledge. In I. Eriksson, B.A. Kitchenham, and K.G. Tijdens (Eds.), Women, work and computerization: Understanding and overcoming bias in work and education (pp. 81-92). Amsterdam: North Holland.

Star, S.L., \& Strauss, A. (1999). Layers of silence, arenas of voice: The ecology of visible and invisible work. Computer Supported Cooperative Work, 8(1-2). 9-30.

Summers, L.H. (2005). Remarks at NBER Conference on Diversifying the Science \& Engineering Workforce. Cambridge, MA. January 14. Retrieved March 5, 2005 from http://www.president.harvard.edu/ speeches/2005/nber.html

Wenger, E. (2000). Communities of practice and social learning systems. Organization, 7(2). 225-248. 